\title{
ESTATUTO INTERNACIONAL DE REPRODUÇÃO ASSISTIDA: UMA INTERVENÇÃO NECESSÁRIA?
}

\author{
INTERNATIONAL STATUS OF ASSISTED REPRODUCTION: A \\ NECESSARY INTERVENTION?
}

Taís Vasconcelos Cidrão ${ }^{\mathrm{I}}$ (i)

Antônio Walber Munizi ${ }^{\text {II }}$

Pollyana Souza Vieira ${ }^{\mathrm{III}}$ (1)

\footnotetext{
I Centro Universitário Christus, Fortaleza, CE, Brasil. Mestra em Direito.

E-mail: taisvcidrao@hotmail.com

${ }^{\text {II }}$ Universidade de Fortaleza, Fortaleza, CE, Brasil. Doutor em Direito. E-mail: walber@unifor.br

III Universidade de Fortaleza, Fortaleza,

CE, Brasil. Mestranda em Direito.

E-mail: pollyanavieira@edu.unifor.br
}

\begin{abstract}
Resumo: $\mathrm{O}$ estudo tem como objetivo analisar a necessidade de elaboração, pelos Estados, de Tratado Internacional sobre Reprodução Assistida. O interesse na pesquisa parte de um estudo em que se constatou que a diversidade cultural, social e religiosa exercem influência significativa na legislação de cada país. Soma-se a esse fato a facilidade de acesso a outros Estados para utilização de técnicas proibida no país de origem. Muito embora se tenha conhecimento desses fatores, não há uma normatização global sobre o tema, o que contribui para a existência de um vácuo legislativo na disciplina internacional. Para tanto, parte-se de uma análise documental do Relatório trienal da Internacional Federation of Fertility Societies, (IFFS), de dados publicados pela Agência de Vigilância Sanitária (ANVISA) sobre a importação de gametas humanos, bem como análise da legislação e jurisprudência internacional sobre o tema. Conclui-se que o aumento do turismo reprodutivo, muito embora atrativo, é uma prática que gera muita insegurança jurídica diante da ausência da regulamentação internacional, razão pela qual defende-se a criação de um tratado ou convenção internacional com vistas a se criar regras basilares de competência territorial e princípios norteadores aos signatários.
\end{abstract}

Palavras-chave: Reprodução Assistida. Tratado internacional de Reprodução Assistida. Ausência de legislação internacional. Direito internacional.

\begin{abstract}
The study aims to analyze the need for the elaboration of a International Treaty on Assisted Reproduction by the States. Interest in the research comes from a study in which it was found that cultural, social and religious diversity exert significant influence on the legislation of each country. Added to this fact is the ease of access to other states to use techniques prohibited in their country of origin. Although these factors are known, there is no global standardization on

the subject, which contributes to the existence of a legislative
\end{abstract}

Recebido em: 30.09.2019

Aceito em: 20.07.2020 
vacuum in international discipline, a fact that has contributed to the increase of legal uncertainty arising from the practice of the activity. Therefore, important is a study on the need for the elaboration of an International Treaty that contains basic and uniform rules on Assisted Reproduction. To this end, it starts from a documentary analysis of the International Federation of Fertility Societies' (IFFS) triennial report, data published by the Health Surveillance Agency (ANVISA) on the importation of human gametes, as well as an analysis of international legislation and jurisprudence. About the subject.

Keywords: Assisted Reproduction. International Treaty on Assisted Reproduction. Absence of international law. International right.

\section{Introdução}

As tecnologias em saúde aplicadas no campo reprodutivo, em especial aquelas que visam a concepção, têm sido incorporadas de forma acelerada em diversos contextos socioculturais, sendo capaz de remodelar práticas e compreensões no tocante a filiação, o uso de material genético de terceiros, a parentalidade, as ideais de autonomia, identidade, dentre outros. Essas tecnologias configuram um mercado global envolvendo empresas transnacionais dos mais variados ramos, tais como clínicas de fertilidade, bancos de sêmen, bancos de embriôes e agências que operam na mediação de material genético de terceiros e de gestação substituta.

Esse cenário, em regra, desenvolve-se a partir do setor privado, com pouca regulação e/ou controle social. Hoje, no Brasil, a matéria com as principais regras do procedimento da Reprodução Humana Assistida (RHA), tem sido dirigida pelo Conselho Federal de Medicina (CFM) por meio da Resolução no . 2.168/2017. É interessante destacar que, em outros países a temática é tratada de forma diversa, por óbvio devido a razões como espaço geográfico, razões éticas, sociais, políticas e culturais.

Com o avanço tecnológico dos meios de transporte, somado a facilidade no acesso as informaçóes, principalmente por meio da internet, observa-se a transposição de fronteiras, pelos pretensos usuários de procedimentos de Reprodução Assistida. Esses sujeitos seguem em busca de tecnologias mais avançadas e de utilização de métodos que, por vezes, são proibidos em seu Estado natal. Ainda, mesmo que certos procedimentos náo sejam proibidos em seu país de origem, é possível que o objetivo do deslocamento seja a obtenção de material genético de indivíduos de outros Estado.

Dessa forma, diante do cenário internacional em que se verifica normas díspares sobre o tema, problemas jurídicos podem se insurgir. Dentre as problemáticas de ordem legislativa e também ética, algumas merecem destaque: qual seria a legislação aplicável nos casos de doação de material genético proveniente de países estrangeiros ou nos casos de anonimato (em que não 
se sabe de onde veio o material genético)? Do país que importou o material genético ou daquele que exportou? E nos casos cessão de útero, qual a normativa adequada? Seria aquela proveniente do país onde o bebê nasce ou dos seus pais biológicos? Sendo assim, o objetivo do presente estudo é um aprofundamento sobre a necessidade de elaboração, pelos países, de um Tratado Internacional que contenha, ao menos, regras gerais sobre a aplicação das técnicas envolvendo o instituto da Reprodução Humana Assistida.

A metodologia utilizada baseou-se em uma análise documental do Relatório trienal da Internacional Federation of Fertility Societies, (IFFS), bem como em dados publicados pela Agência de Vigilância Sanitária (ANVISA) sobre a importação de gametas humanos. Analisouse legislação e jurisprudência internacionais sobre o tema, especialmente nos pontos mais controversos que envolvem o tema, tais como a possibilidade de utilização da técnica para todos os indivíduos e classes, a doação de gametas, a onerosidade da utilização das técnicas, sigilo de dados do doador de material genético e cessão de útero. Para tanto, utiliza-se como referência os países que responderam o último Relatório trienal de 2016, produzido pela Organização Internacional Federation of Fertility Societies (IFFS). Com base nesses dados, parte-se para um diagnóstico acerca da transnacionalidade na utilização dessas técnicas para além do domicílio do indivíduo. E, por fim, realizar-se-á avaliação da necessidade de elaboração de um Tratado Internacional sobre Reprodução Humana Assistida.

Por fim, o desenvolvimento do trabalho fora estruturado em 3 tópicos. O primeiro trata sobre o fenômeno da reprodução assistida dentro do cenário internacional, no qual analisouse como esse fenômeno acontece em diversos países. Posteriormente, comentou-se sobre o turismo reprodutivo e suas possíveis finalidades. E, finalmente, no terceiro foram exploradas as consequências jurídicas da falta de uma regulação uníssona, bem como a real necessidade da elaboração de um documento internacional suficiente para tornar a prática do turismo reprodutivo minimamente seguro para todos os envolvidos no processo.

\section{Da reprodução assistida no cenário internacional}

Embora a reprodução assistida seja considerada uma matéria relativamente nova, um dos aspectos que mais impressiona é a rapidez de sua globalização. Nas últimas duas décadas, pesquisadores têm se debruçado intensamente sobre a forma como essa tecnologia tem sido reconfigurada em diferentes contextos sociais globais, incluindo debates sobre moralidade e aceitabilidade de certas tecnologias, impacto de circunstâncias econômico-sociais e experiências de homens e mulheres diante de tratamentos de infertilidade (RESENDE, [201-], online).

Nesse contexto, com objetivo de compilar informaçóes acerca das diferentes formas de regulamentação da Reprodução Assistida em diversos países, a Federation of Fertility Societies publicou Relatório trienal, em 2016. Dentre os assuntos abordados: a quem se aplica as técnicas 
de RHA, normatização da doação de gametas, onerosidade e sigilo de dados do doador, cessão temporária de útero etc.

Dessa forma, após a leitura do Relatório, de legislaçôes e julgados estrangeiros (que serão apreciados mais a frente), é possível afirmar que há diversidade de entendimento quanto ao tema a depender da cultura, religião e costume de cada país. Constata-se que a diversidade de entendimentos toca desde os assuntos mais simples, como a possibilidade ou não da utilização das técnicas de RHA, até aspectos mais polêmicos, como a possibilidade de utilização da tecnologia para todos os indivíduos e classes.

Em um aspecto geral no que diz respeito a utilização das técnicas de Reprodução Assistida, tem-se o caso Artavia Murillo e outros vs Costa Rica, julgado em 28 de novembro de 2012 (CORTE INTERAMERICANA DE DIREITOS HUMANOS, 2012, online). O fato foi levado à Corte Interamericana de Direitos Humanos (doravante denominada CIDH) para contestar a decisão da Corte Suprema de Justiça do Estado da Costa Rica, que por sua vez entendeu, na interpretação do artigo 21 da Constituição daquele Estado ${ }^{1}$, que as técnicas que levam à concepção em laboratório violam o direito à vida e à dignidade humana; direitos estes que estariam protegidos desde a concepção. Com base nesse entendimento, a Corte daquele determinou a proibição da utilização das técnicas de fertilização em vitro (FIV) no país.

$\mathrm{O}$ argumento utilizado na decisão da $\mathrm{CIDH}$ foi no sentido de reconhecer a existência de um direito à vida privada, familiar, protegido pela Convenção Americana de Direitos Humanos e que, portanto, a proibição imposta pelo Estado da Costa Rica quanto à prática da fertilização in vitro viola tais direitos. Dessa forma, responsabilizou o Estado e determinou a adoção de medidas administrativas, bem como legais, para permitir a realização da FIV.

Por outro lado, nos países em que há o entendimento pela possibilidade de utilização da técnica de RHA, um dos principais desacordos no que diz respeito à regulamentação, de acordo com o Relatório da IFFS, é quanto ao público que pode se beneficiar da utilização das técnicas. No Brasil, não há distinção pelo gênero, nem exigência de relação estável heterossexual. Nesse mesmo sentido é a normativa da Austrália, Bélgica, Canadá, México, Paraguai, Peru, África do Sul, Reino Unido e Estados Unidos da América.

Já em países como Jordânia, Bangladesh, Arábia Saudita, Indonésia e Irã, há a exigência de relacionamento estável heterossexual, sendo que, dentre os países que permitem a utilização das técnicas somente por casais heterossexuais, fundamentam a proibição em decretos religiosos.

No tocante à permissão de doação de gametas para sua utilização em reprodução heteróloga, ou seja, aquela que é feita com material genético de terceiro, a Itália passou a permitir a doação somente do ano de 2014. A Alemanha, Japão, Noruega e Suíça permitem a doação de espermatozoides, sem fazer o mesmo, entretanto, com a doação de óvulos. Sobre esse quesito, apenas Israel reflete posicionamento oposto, ou seja, permite a doaçáo de óvulos, mas estabelece restrições quanto à doação de espermatozoides. Países como Bangladesh, El Salvador, Jordânia,

1 Que prolata, verbis: "La vida humana es inviolable" (COSTA RICA, 1949, online). 
Filipinas, Arábia Saudita, Senegal, Tunísia e Turquia proíbem a prática. No Brasil, a doação de oócito, bem como espermatozoide e de embrião é permitida, desde que realizada de forma gratuita.

Ainda sobre pontos polêmicos envolvendo a temática, tem-se o anonimato dos doadores e filhos. Constatou-se, na comparação com o relatório de 2013, mudanças de entendimento em alguns países. Nesse sentido verificou-se a tendência a se divulgar mais informaçóes sobre os doadores para futuros pais e futuros filhos, ou de filhos para doadores. Hoje, esses dados são fornecidos livremente e abertamente em alguns países, como, por exemplo, no Reino Unido, na Austrália e na Bélgica. Nos países europeus inquiridos no relatório de 2016, com exceção da Irlanda, há leis nacionais que exigem divulgação de informaçóes relativas a doadores ou descendentes, embora haja diferenças quanto à natureza da informação divulgada.

$\mathrm{Na}$ Argentina, no ano de 2013, a Lei no 26.862 de 2013, que disciplina a Reprodução Assistida naquele país, trouxe modificaçóes no Código Civil para incluir a filiação da tecnologia de RHA. Deixou aberta a possibilidade para que, diante uma interpretação extensiva do artigo $564^{2}$, os filhos provenientes da técnica possam solicitar dados não identificáveis do doador, mas somente em casos justificáveis e mediante ordem judicial (INTERNATIONAL FEDERATION OF FERTILITY SOCIETIES, 2016, p. 43). Na Espanha, o artigo 8º, n.3 Lei no. 14/2006, que regulamenta a Reprodução Assistida, dispóe que a revelação da identidade do doador é possível, porém não implicará, necessariamente, a determinação legal da filiação, verbis:

Art. 8

La revelación de la identidad del donante en los supuestos en que proceda conforme al artículo 5.5 de esta Ley no implica en ningún caso determinación legal de la filiación. (ESPANHA, 2006, online).

Já no Brasil, embora existam alguns Projetos de Lei em trâmite, com o objetivo de criar um "Estatuto da Reprodução Assistida", tais como: PL 4686/2004, PL 2855/1997, PL 120/2003, PL 5624/2005, PL 3977/2012, PL 4892/2012, PL 115/2015, PL 7591/2017, PL 9403/2017, dentre outros (CÂMARA DOS DEPUTADOS, 2019, online), hoje, somente a Resolução n. 2.168/2017 do Conselho Federal de Medicina dispóe sobre a matéria. Nessa normativa, há proibição expressa da divulgaçáo de dados pessoais para resguardar o sigilo da identidade do doador do material genético.

2 Articulo 564: Contenido de la información. A petición de las personas nacidas a través de las técnicas de reproducción humana asistida, puede:

a) obtenerse del centro de salud interviniente información relativa a datos médicos del donante, cuando es relevante para la salud;

b) revelarse la identidad del donante, por razones debidamente fundadas, evaluadas por la autoridad judicial por el procedimiento más breve que prevea la ley local. (ARGENTINA, 2014, online). 
Será mantido, obrigatoriamente, sigilo sobre a identidade dos doadores de gametas e embrióes, bem como dos receptores. Em situaçóes especiais, informaçóes sobre os doadores, por motivação médica, podem serfornecidas exclusivamente para médicos, resguardando-se a identidade civil do(a) doador(a). (CONSELHO FEDERAL DE MEDICINA, 2017, online).

Por outro viés, dentre os Projetos de Lei mencionados, o Projeto $n^{\circ}$. 1184/2003 de autoria do ex-senador Lúcio Alcântara, prevê a possibilidade de o indivíduo conhecer a doador, se assim o quiser.

Outra divergência que merece destaque é a possibilidade de pagamento por doações de gametas (compensation for donors), ou seja, a possibilidade de o indivíduo receber valores ao disponibilizar seus espermatozoides ou óocitos para a utilização, por terceiros, na técnica de Reprodução Humana. O Relatório apontou que na maioria dos países é possível se compensar financeiramente o tempo e despesas decorrentes do procedimento, o que varia amplamente é o valor dessa compensação. Há Estados, como por exemplo Canadá, França e Japão em que a compensação é ilegal. Por outro lado, há países em que se é estabelecido valores mínimos e máximos para compensação (Colômbia, Grécia e Guatemala). Há, ainda, países (a exemplo de Israel) em que o valor é tabelado pelo Ministério da Saúde. (INTERNATIONAL FEDERATION OF FERTILITY SOCIETIES, 2016, p. 43). No que diz respeito ao Brasil, a Resolução n. 2.168/2017, é clara, no seu capítulo IV, ao dispor que não haverá nenhum tipo de pagamento ao doador de gametas. (CONSELHO FEDERAL DE MEDICINA, 2017, online).

No tocante a cessão de útero, popularmente conhecida como "barriga de aluguel" (situação em que uma mulher gesta o bebê de outra), poderá ser realizada de forma altruísta ou com fins comerciais. No Brasil, com autorização da Resolução no 2.168/2017, é permitida a doação reprodutiva intrafamiliar, inclusive, o Enunciado no 45 (aprovado na I Jornada de Direito da Saúde do CNJ) dispóe que "nas hipóteses de reprodução humana assistida, nos casos de gestação de substituição, a determinação do vínculo de filiação deve contemplar os autores do projeto parental, que promoveram o procedimento" (CONSELHO NACIONAL DE JUSTIÇA, 2014, online). Muito embora, tenha um Projeto de Lei atualmente em trâmite, de $n^{\circ}$. 1184/2003, que veda toda e qualquer forma de gestação de substituição.

A legislação espanhola, já mencionada anteriormente, no seu artigo $10.1^{3}$ proíbe qualquer contrato que tenha por objeto a gestação por substituição e o inciso posterior, $10.2^{4}$ determina que mãe é aquela que deu à luz, pois a filiação dos nascidos por gestação de substituição deve ser determinada pelo parto. Seguindo entendimento diverso, Portugal, por meio do art. $8^{\circ}$ da Lei $n^{\circ}$ 25/2016 (PORTUGAL, 2016, online), permite a gestação por substituição em caos excepcionais

\footnotetext{
3 Artículo 10. Gestación por sustitución.

1. Será nulo de pleno derecho el contrato por el que se convenga la gestación, con o sin precio, a cargo de una mujer que renuncia a la filiación materna a favor del contratante o de un tercero.

4 A rtículo 10. Gestación por sustitución.

2. La filiación de los hijos nacidos por gestación de sustitución será determinada por el parto.
} 
de comprovada impossibilidade da mãe biológica em gestar, outros países como Estados Unidos e Suécia a prática também é permitida.

Diante desse cenário, o indivíduos ou o casais que se veem impossibilitados de realisar tais procedimentos no país de sua residência, aderem à ideia de se deslocar para países cuja legislação é permissiva. E, especialmente em situações como esta, surgem alguns questionamentos acerca da filiação e da cidadania das crianças geradas frutos desse tipo de concepçáo que merecem reflexão.

Conforme explicaçóes nos parágrafos anteriores, percebe-se que as práticas locais de Reprodução Humana Assistida variam significativamente entre países, seja por razóes culturais, religiosas, políticas e/ou econômicas. O fato de que os Estados podem regulamentar diferentemente a utilização das técnicas de RHA, somado à facilidade cada vez maior de transpor fronteiras para a realização do procedimento em outro país, faz com que os indivíduos procurem, cada vez mais, novas técnicas ou diferentes regulamentaçôes, a fim de evitar as restrições impostas pelo seu país de origem.

\section{Da transposição de fronteiras na utilização das técnicas de reproduçáo assistida}

Em razão da diferença decorrente do nível tecnológico e normativo de cada país, a reprodução assistida atrai pessoas do mundo inteiro. A prática de viajar para se utilizar de técnicas estrangeiras ou até mesmo utilizar o material genético de pessoas com nacionalidade diversa, através da importação de gametas, incentivam o que Lisa C. Ikemoto (2009, p. 278) denominam de "turismo de reprodutivo". Os professores destacam que, por inúmeras e complexas razóes, tais como o alto custo do serviço de RHA, escassez tecnológica ou até mesmo questóes relacionadas ao sigilo do doador, os pretensos usuários das técnicas de fertilidade deixam suas jurisdiçôes domésticas para utilizar os serviços em outro país.

Nesse contexto, verifica-se que o Brasil é um dos países que, seguindo o trilho da globalização, faz parte do novo fenômeno social do "turismo da fertilidade". Ou seja, há o deslocamento de pessoas, de técnicas, de capital e de tecidos com o intuito de serem utilizados no tratamento da infertilidade. É o que acontece, por exemplo, nos casos de importação de gametas ou embriōes disponíveis em Bancos de Células e Tecidos Germinativos de outros países.

No Brasil, a regulamentação técnica desses Bancos é disciplinada pela Agência Nacional de Vigilância Sanitária - ANVISA, por meio da Resolução no ${ }^{\circ} 23$ de 27 de maio de 2011, cujo objetivo é "instituir critérios mínimos para o funcionamento dos Bancos de Células e Tecidos Germinativos (BCTG) visando a segurança e qualidade das células, tecidos germinativos e embrióes utilizados" (ANVISA, 2011, online). Sendo que, através da normativa no ${ }^{\circ} .81$ de 5 de novembro de 2008, que dispóe sobre o Regulamento Técnico de Bens e Produtos Importados para fins de Vigilância Sanitária, a importação de material advindos de doadores estrangeiros já havia sido regulamentada (ANVISA, 2008, online). 
Interessante perceber que, apesar do artigo $199 \$ 4^{\circ}$ da Constituição Federal de 1988 estatui que:

Art. 199.

\section{$[\ldots]$}

$\$ 4^{\circ}$ A lei a disporá sobre as condições e os requisitos que facilitem a remoção de órgãos, tecidos e substâncias humanas para fins de transplante, pesquisa e tratamento, bem como a coleta, processamento e transfusão de sangue e seus derivados, sendo vedado todo tipo de comercialização.

A única regulamentadora atualmente vigente, a de no. 9434/97 (Lei Transplante), afirma, em seu artigo $1^{\circ}$ parágrafo único, que não estão compreendidos entre os tecidos o sangue, $\mathrm{o}$ esperma e o óvulo. Dessa forma, o regramento sobre o transporte de esperma e óvulo coube às Resoluções da ANVISA.

Com a responsabilidade sobre o controle e regulamentação do assunto, a ANVISA periodicamente disponibiliza Relatórios com informaçôes pertinentes à temática. E, de acordo com informaçôes do $2^{\circ}$ Relatório de dados de importação de células e tecidos germinativos para uso em reprodução humana assistida, houve um aumento significativo das importaçôes de gametas e embriôes. Sendo que, em relação às amostras de oócitos, o aumento foi de aproximadamente $1.359 \%$, considerando os períodos de 2015-2016. No que se refere ao sêmen, no período 2016-2017, o aumento foi de 97\% (ANVISA, 2018, online).

Um dos Projetos de Lei em trâmite no Congresso Nacional (PL 4892/2012) limita, no seu artigo $5^{\circ}$, a utilização das técnicas da RHA para fins terapêuticos da infertilidade ou esterilidade. Ou seja, caso o referido projeto seja aprovado, essa restrição pode impulsionar o "turismo da fertilidade", tendo o Brasil como país de origem e outros Estados, que não proíbam a utilização da técnica por pessoas férteis, como os destinos.

Segundo Ikemoto (2009, p. 297), o fenômeno do turismo reprodutivo expandiu-se rapidamente em escala mundial e tornou-se um negócio altamente lucrativo. Dentre as razôes que tornaram as técnicas de reprodução assistida um negócio rentável, pode-se destacar a procura pelo menor custo ou maior qualidade procedimental, facilidade no envolvimento de terceiras partes (doadores e grávidas em substituição) etc. Desse fato, tem surgido uma verdadeira indústria, formada por médicos, hospitais, clínicas, bancos de esperma, agenciadores e intermediadores (que direcionam os serviços para atender uma demanda estrangeira), cada qual trabalhando na sua área de expertise visando a diminuição das barreiras e restriçôes internacionais. E nesse mercado global, já é possível identificar grupos transnacionais, como a Nordica’s IVF Fertility Center, que opera na Dinamarca, Lituânia e Nigéria.

A professora (IKEMOTO, 2009, p. 300) detectou ainda motivação puramente econômica, tendo como principal exemplo a Índia, país ainda em desenvolvimento, no qual, em razão das desigualdades sociais, as mulheres, pela necessidade financeira, cedem o útero para dar à luz de crianças de outras mulheres. A Dinamarca, país onde o anonimato do doador de 
gametas é garantido, é um país bastante procurado pelo seu mercado de Reprodução Humana, recebendo grande número de visitantes advindos da Suécia, Noruega e também Alemanha, onde não se permite o anonimato dos doadores.

Do exposto, extrai-se que o turismo reprodutivo é uma preocupação global, sendo que, caso a legislação de determinado país seja restritiva, a ponto de proibir intervenção de terceira parte no processo reprodutivo, seja por doação de esperma, de óvulos ou até mesmo no que diz respeito à gestação de substituição, aqueles que não se encaixam no perfil traçado pela legislação irão buscar, nos países de destino reprodutivo, as soluçôes cabíveis para as respectivas problemáticas (GUIMARÃES, [201-], online). Por esse motivo, os Estados terão que enfrentar os debates advindos dessa assimetria legislativa. Nessa situação, terá que ser analisada a (in) viabilidade de uma política internacional unificada capaz de diminuir (ou até impedir) práticas, pelos Estados, violadoras de certos direitos universais.

\section{Da necessidade da elaboraçáo de tratado internacional sobre reproduçáo assistida}

Partindo da premissa em que há coexistência de diferentes ordenamentos jurídicos e, portanto, há a necessidade de conciliar os conflitos normativos existentes entre os Estados, a elaboração de Tratados Internacionais é a medida salutar para resolução desses conflitos.

Por Tratado, entende-se o acordo de vontade entre dois ou mais sujeitos de direito internacional. Tal pacto é celebrado por escrito, com objetivo de produzir efeitos jurídicos sob a égide do direito internacional, independentemente de sua designação específica (GOMES, 2016).

A forma como os Tratados Internacionais serão elaborados e ratificados, sua eficácia, aplicação e interpretação, está regulada na Convenção de Viena sobre Direito dos Tratados de 1969, promulgada pelo Brasil pelo Decreto 7.030/2009 (BRASIL, 2009, online), que regula o processo de formação dos tratados desde a fase inicial de negociaçôes preliminares até a sua conclusão, com as devidas assinaturas, a aprovação parlamentar por parte de cada Estado interessado, a ratificação e, por fim, a promulgação.

Sobre a obrigatoriedade na aderência, há que se destacar que nenhum país é obrigado, pela comunidade internacional, a aderir determinado tratado internacional. A decisão, portanto, é decorrente da vontade soberana dos respectivos Estados. Dessa forma, diante da coexistência de diferentes ordenamentos jurídicos (e, consequentemente, de soberanias), especialmente no que diz respeito à reprodução assistida, difícil é prever se as normas previstas em um tratado internacional seriam aceitas de forma unânime pela maioria dos Estados.

De acordo com artigo $9^{\circ}$ da Convenção de Viena, os Tratados internacionais com mais de duas partes, são elaboradores em conferências e eventos internacionais, onde é discutido o objeto do acordo e, posteriormente, levado a produção do texto que, para ser aprovado, necessita 
de no mínimo 2/3 dos presentes e votantes, salvo se esses Estados, pela mesma maioria, decidirem aplicar uma regra diversa.

No Brasil, a competência para a celebração dos tratados internacionais está expressa no artigo 84, inciso VII, da Constituição Federal de 1988. Compete privativamente ao Presidente da República "celebrar tratados, convençóes e atos internacionais, sujeitos a referendo do Congresso Nacional” (BRASIL, 1988, online).

No âmbito internacional, há alguns Tratados e Convençôes que dispóem sobre bioética, tais como: proteção jurídica do genoma humano e os Direitos Humanos (UNESCO -97); Declaração Internacional sobre Dados Genéticos Humanos (UNESCO - 2003); Declaração Universal de Bioética e Direito Humanos (UNESCO - 2005); a Declaração das Naçóes Unidas sobre Clonagem Humana (ONU - 2005) e, ainda, no âmbito da comunidade europeia, além da Convenção dos Direitos do Homem e da Biomedicina (1997), a Carta de Direitos Fundamentais da União Europeia (2000) (PETTERLE, 2007). Contudo, mesmo diante da problemática do "turismo reprodutivo" apresentada nas seções anteriores, não há nenhum instrumento internacional que disponha especificamente sobre a temática ora discutida.

As problemáticas causadas pelas assimetrias legislativas de um Estado para outro merece a atenção, análise e solução pela comunidade internacional, uma vez que a falta de regulamentação gera insegurança jurídica (para os pais biológicos quanto à filiação, quanto para mãe que cedeu o útero, mas, principalmente, para a criança quanto à incerteza de seu destino).

Nesse sentido, outras consequências jurídicas podem advir da falta de regulamentação, tais como 1) a possibilidade de ser negada a cidadania dos filhos nascidos em países estrangeiros, frutos de uma gravidez com cessão do útero; 2) dúvidas sobre a legislação cabível nos casos de doação de gametas provenientes de outro país; 3) qual será a normativa aplicável nos casos de reprodução heteróloga em que é permitido o anonimato no país do doador, mas não há do Estado em que a criança nasceu (ou vice-versa); 4) nos casos de cessão de útero envolvendo legislaçôes diversas, a melhor lei aplicável seria a do país dos pais biológicos ou da mãe em substituição? 5) Em se tratando da determinação da nacionalidade, em que o critério considerado é jus sanguinis, a criança proveniente de material genético vindo do estrangeiro, também teria direito à nacionalidade do país do doador?

Questionamento como esses permanecem sem resposta, fato que enfraquece as relaçóes jurídicas advindas das técnicas de reprodução assistida em vez de fortalecê-las, ao passo que, por outro lado, deixa às empresas transnacionais, que se utilizam desse mercado, a responsabilidade de "disciplinar", onde for possível, essas relaçôes.

Com a elaboração de um tratado ou convenção internacional sobre o tema, além de um conjunto de princípios gerais para orientação dos Estados signatários, deve constar respostas básicas a esses questionamentos, ou seja, regras mínimas para se estabelecer disposição sobre a competência territorial dos Estados, dando, assim, maior segurança jurídica para aqueles que optam pela reprodução assistida. 


\section{Consideraçóes finais}

A falta de unificação no que concerne à regulação internacional existente no campo da reprodução assistida e o crescente aumento da demanda pelas práticas que envolvem a necessidade de material genético de terceiros ou, em algumas situaçôes, até mesmo o próprio corpo (como no caso da gravidez em substituição), faz com que pessoas de diferentes partes do mundo busquem em outros países o sonho de concretizar a maternidade e/ou a paternidade biológica.

Nesse cenário, verifica-se a disparidade normativa entre Estados, no campo da reprodução assistida, pode advir de questóes religiosas, sociais e/ou culturais. No entanto, com os avanços tecnológicos, dos meios de transporte, somada à facilidade no acesso às informaçóes, houve a transposição de fronteiras. Pessoas de diferentes países começaram a viajar em busca de acesso aos instrumentos que permitem a geração de filhos biológicos, fato conhecido hoje como "turismo de fertilidade" ou "turismo reprodutivo". Esse fenômeno, embora atrativo, diante da ausência de regulamentação internacional gera muita insegurança jurídica para aqueles que buscam no serviço a solução para a proibição de certas práticas reprodutiva em seu país de origem.

Por esse motivo, surge a necessidade de elaboração de tratado ou convenção internacional, em que se estabeleçam regras basilares sobre a competência territorial e se imponham princípios gerais para orientação dos Estados signatários.

\section{Referências}

ANVISA. 2 o Relatório de dados de importaçáo de células e tecidos germinativos para uso em reproduçáo humana assistida. Brasília, 2018. Disponível em: http:// portal.anvisa.gov.br/documents/4048533/5235041/2\%C2\%BA+Relat\%C3\%B3rio+de +Importa\%C3\%A7\%C3\%A3o+-+Reprodu\%C3\%A7\%C3\%A3o+Humana+Assistida+ 2018/1b0811da-de21-4975-9522-b2458a73ec53. Acesso em: 17 ago. 2019.

\section{ANVISA. Resoluçáo da Diretoria Colegiada - RDC no 81 de 5 de novembro}

de 2008. Dispóe sobre o regulamento técnico de bens e produtos importados para fins de vigilância sanitária. Disponível em: http://portal.anvisa.gov.br/ documents/33880/2568070/rdc0081_05_11_2008.pdf/a02a1a3f-eaf1-4264-b1c0084eb426fc37. Aceso em: 24 jul. 2019.

ANVISA. Resoluçáo no 23 de 27 de maio de 2011. Dispóe sobre o regulamento técnico para o funcionamento dos Bancos de Células e Tecidos Germinativos e dá outras providências. Disponível em: https://www.diariodasleis.com.br/busca/exibelink. php?numlink=217983. Acesso em: 27 jul. 2019.

ARGENTINA. Ley 26.994 de $1^{\circ}$ de outubro de 2014. Código Civil y Comercial de la Nación. Disponível em: http://servicios.infoleg.gob.ar/infolegInternet/ anexos/235000-239999/235975/norma.htm\#15. Acesso em: 20 set. 2019. 
ARGENTINA. Ley Nacional de Fertilización Humana Assistida no. 26.862 de 25 de junho de 2013. Dispóe sobre o acceso integral a los procedimientos y técnicas médico-asistenciales de reproducción médicamente asistida. Disponível em: http:// servicios.infoleg.gob.ar/infolegInternet/anexos/215000-219999/216700/norma.htm. Acesso em: 16 set. 2019.

BRASIL. [Constituição (1988)]. Constituição da República Federativa do Brasil. Organizado por Cláudio Brandão de Oliveira. Rio de Janeiro: Roma Victor, 2002. 320 p.

BRASIL. Câmara dos Deputados. Resultado de consulta pública por "Reproduçáo Assistida”. Projetos de Lei: PL 4686/2004, PL 2855/1997, PL 120/2003, PL 5624/2005, PL 3977/2012, PL 4892/2012, PL 115/2015, PL 7591/2017, PL 9403/2017 dentre outros. Disponível no site: http://www.camara.gov.br/ proposicoesWeb/fichadetramitacao?idProposicao=118275\&ord=1. Acesso em: 24 set. 2019.

BRASIL. Decreto no 7.030 de 14 de Dezembro de 2009. Promulga a Convenção de Viena sobre o Direito dos Tratados, concluída em 23 de maio de 1969, com reserva aos Artigos 25 e 66. Disponível em: http://www.planalto.gov.br/ccivil_03/_Ato20072010/2009/Decreto/D7030.htm. Acesso em: 24 set. 2019.

CONSELHO FEDERAL DE MEDICINA. Resolução n. 2.168 de 10 de novembro de 2017. Adota as normas éticas para a utilização das técnicas de reprodução assistida - sempre em defesa do aperfeiçoamento das práticas e da observância aos princípios éticos e bioéticos que ajudam a trazer maior segurança e eficácia a tratamentos e procedimentos médicos -, tornando-se o dispositivo deontológico a ser seguido pelos médicos brasileiros e revogando a Resolução CFM no 2.121, publicada no D.O.U. de 24 de setembro de 2015, Seção I, p. 117. Diário Oficial da União, seção I, p. 73, 10 out. 2017. Disponível em: https://sistemas.cfm.org.br/normas/visualizar/resolucoes/ BR/2017/2168. Acesso em: 15 set. 2019.

CONSELHO NACIONAL DE JUSTIÇA. I Jornada em Direito À Saúde. 2014, São Paulo. Enunciados aprovados. São Paulo: Tribunal de Justiça de São Paulo. Disponível em: https:/www.cnj.jus.br/images/ENUNCIADOS_APROVADOS_NA_ JORNADA_DE_DIREITO_DA_SAUDE_\%20PLENRIA_15_5_14_r.pdf. Acesso em: 30 ago. 2019.

CORTE INTERAMERICANA DE DIREITOS HUMANOS. Sentença de 28 de novembro de 2012 no caso Artavia Murillo e outros vs. Costa Rica. Disponível em: http://www.corteidh.or.cr/docs/casos/articulos/seriec_257_por.pdf. Acesso em: 04 abr. de 2019.

COSTA RICA. [Constituição (1949)]. Constitución política

de Costa Rica. Disponível em: http://www.pgrweb.go.cr/ scij/Busqueda/Normativa/Normas/nrm_texto_completo. 
aspx?param $1=$ NRTC\&nValor1 $=1 \&$ nValor2=871\&nValor3=95479\&strTipM=TC .

Acesso em: 25 ago. 2019.

ESPANHA. Lei no 14 de 26 de maio de 2006. Dispóe sobre regras de reprodução humana assistida. Disponível em: https:/www.boe.es/buscar/act. php?id=BOE-A-2006-9292. Acesso em: 21 set. 2019.

GOMES, Eduardo Biacchi. Introdução aos Estudos de Direito Internacional. $1^{\mathrm{a}} \mathrm{ed}$. Curitiba: Editora Intersaberes, 2016.

GUIMARÃES, Cláudia Maria Resende Neves G. A Third-party na reprodução assistida: perspectivas globais, diversidade cultural e mercado reprodutivo transnacional. [S.1], [201-]. Disponível em: http://www.publicadireito.com.br/ artigos/?cod=1908ffe453edcfd0. Acesso em: 20 ago. 2019.

IKEMOTO, Lisa C. Services Reproductive Tourism: Equality Concerns in the Global Market for Fertility Services. Law and Inequality: A Journal of Theory and Practice, Vol. 27, no 2, 2009. Disponível em: https://papers.ssrn.com/sol3/papers.cfm?abstract_ id=1462477. Acesso em: 12 set. 2019.

INTERNATIONAL FEDERATION OF FERTILITY SOCIETIES. Global Reproductive Health. Vol. 1 - Issue 1 - p. 1-143 set. 2016. Disponível em: https:// journals.lww.com/grh/Fulltext/2016/09000/IFFS_Surveillance_2016.1.aspx. Acesso em: 14 jul. 2019.

PETTERLE, Selma Rodrigues. $\mathbf{O}$ direito fundamental à identidade genética na Constituição brasileira. Porto Alegre: Livraria do Advogado, 2007.

PORTUGAL. Lei n.o 25 de 22 de agosto de 2016. Regula o acesso à gestação de substituição, procedendo à terceira alteração à Lei n.o 32/2006, de 26 de julho (procriação medicamente assistida). Diário da República, 1. ${ }^{a}$ série - N.o 160. Disponível em: https:/dre.pt/application/conteudo/75177806. Acesso em: 29 abr. 2019. 